\title{
Promote the Construction of University Culture and University Spirit to \\ Enhance the Competitiveness of the Colleges and Universities
}

\author{
Meng Qinghe \\ Jilin Institute of Chemical InDustry \\ Jilin City,Jilin Province, China \\ E-mail: 232063869@qq.com
}

\begin{abstract}
University is a kind of culture. The source of improving the core competitiveness is the construction of university culture. There is only one core and soul of the university culture, which is university spirit. University want to improve its core competitiveness, the basic point lies in the improvement of the university itself, explain and cultivate university spirit with a new concept, foster and enhance the core competitiveness of university with university culture and spirit, especially, school should pay attention to put their core values and university spirit as the focus of the university cultural construction and pay attention to refine the school-running idea to find out the accurate position for development and keep the innovation education idea. Also should attach great importance to the university image design and initiate behavior culture.
\end{abstract}

Key words: university cultural, university spirit, the core competitiveness

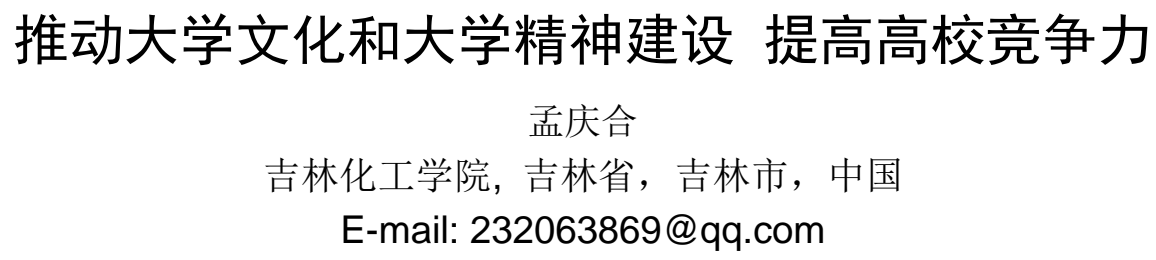

中文摘要. 大学即文化。大学文化建设是提 升大学核心竞争力的源泉。大学文化的核心 和灵魂只有一个, 即大学精神。大学要提升 自己的核心竞争力，根本点在于大学自身的 完善，用一种新的观念来诠释、培育大学精 神。用大学文化和大学精神来培育和提升大 学的核心竞争力, 尤其应当重视是要把提炼 学校的核心价值观和培育大学精神作为大学 文化建设的重点, 要注重提炼学校的办学理
念，对发展准确定位，要不断创新教育理念， 还要重视大学形象设计, 倡导行为文化。

关键词: 大学文化 大学精神 核心竞争力

1. 引言

大学不仅是一种客观的物质存在，更是 一种文化存在和精神存在。文化是一个大学 赖以生存、发展的重要根基和血脉，也是大 
学间相互区别的重要标志和特征。伴随 21 世 纪的新科技革命, 高校的功能和面貌发生了 前所未有的深刻变化, 大学文化和大学精神 建设越来越受到重视。可以说, 大学文化与 大学精神的力量, 已经深深地熔铸在高校的 生命力、创造力和感召力之中。大学要提升 自己的核心竞争力, 根本点在于大学自身的 完善, 用一种新的观念来诠释、培育、塑造 大学文化和大学精神。

\section{2. 大学文化和大学精神的内涵和特征}

大学文化是大学在长期发展变革过程中 形成的物质文化和精神文化的总和。它有两 层含义, 一个层次是指关于大学的文化, 是 一个类的概念, 表明其产生于大学, 与大学 相互依存。大学文化的另一个层次是指大学 内的文化, 是一个个体的概念, 指某一大学 个体的文化, 是大学文化个性化的一面。尊 崇共性是大学文化建设的根本, 培养个性是 大学赖以生存和发展的保证。大学文化是以 大学为载体, 通过历届师生的传承与创造, 为大学所积累精神成果和蕴涵这种精神成果 的物质成果的总和, 它集中体现在全校师生 和全体校友的科学文化、思想道德和精神文 明等方面的素养之中。因此, 大学文化是以 大学为载体、以大学师生为主体的文化。大 学理念和价值观是大学文化的核心, 大学传 统和精神是大学文化的灵魂, 学生的文化素 质、教师的文化修养、学校的文化品位是大 学文化的标志。大学文化的内核是大学精神。 大学精神就是建立在一定大学制度和浓厚大 学文化基础之上的一种精神积淀, 是一所大 学体现出来的生命力、创造力和凝聚力的整 体精神面貌。德国洪堡在创建柏林大学时提 出的 “学术自由” “大学自治” “教授治校” “教学与科研统一” 的办学思想, 被视为是 大学最具共性的基本价值和制度特征。现代 大学制度其实还有一个重要特点, 即 “学生 自治”。大学生的自我管理和民主管理, 不仅 是一种公民教育, 也与大学所追求的创造性 和个性发展的目标是一致的, 是大学校园文 化中最重要的机制。大学创造知识和传承知 识的终极目的, 是为了推动人类的文明进步, 使人能够得到真正意义上的全面发展。因而, 大学总是把人类的未来作为自己的建设对象, 充满了对人类命运的终极关怀, 充满了对自
己民族、对社会、对整个世界的责任意识和 使命意识。与普通的商业文化、时尚文化、 消费文化等相比较, 大学文化和大学精神在 特征上就表现为: 它是追求真理、追求自由、 倡导民主、崇尚科学、富于批判等精神因素 的整合; 它是有利于滋养人的人格、理想, 孕育超越的精神文化，以此为社会设立一个 精神价值尺度, 并从根本上引导着社会进 步。

特征之一：追求真理。大学作为一种社 会的最高教育形式, 应以传承、整理和创新知 识为己任，是知识的集散地和创造源。而创 造知识的过程, 就是追求真理、坚持真理、 捍卫真理的过程。追求真理可以说是大学的 精神和生命, 否则, 大学就失去了本真的意 义，成为雅斯贝斯所说的 “纯粹的职业训练 的场所”。

特征之二：追求自由和民主。大学追求 自由和民主的文化精神, 主要体现在学术 上。追求自由的文化精神, 不仅意味着学术 要从政治的怀抱中自由出来, 而且还意味着 要从大学里的各种束缚中挣脱出来。学术自 由是学者追求真理的先决条件, 学术的自由 带来学术的繁荣, 学者与学子要在这种文化 气息的熏陶和鼓励下自由地传授与学习人类 文明的各种知识，自由地进行理性思考和探 讨, 然后在这种开放的环境中积极地进行创 造，体现出 “万物并育不相害，道并行而不 相悖” 的原则。大学倡导民主的文化精神, 即 指大学追求校园民主与社会民主进步的精 神。民主，强调人的自由、自主、平等与进 步, 强调人性的尊严与个性的发展。大学的 民主精神还表现在管理上，在一定合理范围 内，大学有权决定自己的教育目标、发展目 标和学校内部的运行管理; 大学的民主提倡 法制与制度创新，其校长、教师、学生都是 学校的主人, 都有权利与义务为大学的发展 做出自己的贡献, 追求大学的法治。大学的 民主精神，提倡充分发展学生的能力与个性, 并追求创造一个民主进步的社会，促进社会 的全面进步与发展。

特征之三：追求理想和责任。大学传播 和流行社会中最进步、最深刻、最文明的思 想、意识和精神, 这些思想、意识、精神的 传播、感染和熏陶，奠基着受教育者崇高的 
人格目标和高尚的人生价值观基础。这种人 生价值观和人格目标往往因其远远超过了现 实的社会思想水平, 极具理想性。大学教育 始终以全社会、全人类、整个民族或者整个 国家为自己的思想目标, 以人类、社会的未 来为自己的建设对象, 因而远离世俗的生活 和具体的物质利益, 能够张扬人类最美好的 信念和情感, 鄙视自私、贪婪、剥削、压迫、 欺计等丑行。它能引导人变得纯洁和高尚, 能使人追求美好的情感和境界, 能使人形成 追求真、善、美的凝聚力和向心力, 形成追 求高尚和文明的自觉性。同时, 大学作为社 会文化和思想的中心, 聚集了社会中大部分 的思想家和文化精英, 因而形成了强烈的社 会责任意识。

特征之四: 强烈的批判精神。大学的活 动, 主要是进行人与自然、人与宇宙、人与 规律、人与逻辑、人与道德、人与社会、人 与命运的思辨和对话。这种思辨与对话本身 就是一个严谨的学术过程。因此, 大学鄙视 浅薄、浮躁、虚假、急功近利和随波逐流, 崇 尚严谨、逻辑、实证、经验, 崇尚脚踏实地, 一步一个脚印地艰苦攀登和勤奋工作。大学 的批判精神是大学创新精神的实质, 是大学 所应具备的本质理念, 也是创新人才应具备 的基本品质。实际上, 批判、前瞻和引导的 功能是未来大学责任与使命的最高境界的体 现, 它所依赖的批判精神应该是新世纪大学 的理想和追求。批判精神的主要特征是求异 与超越, 是大学存在的价值所在, 是大学在 社会有机体中保持自身地位和生命力的法 宝。批判精神使教师在工作的过程中能够以 严谨而科学的态度对待传统与现实, 不盲从; 使学生在学习的过程中不唯书、不唯上, 只 唯实。

\section{3. 高校激烈竞争凸显大学文化和大学精神对 提升其核心竞争力的作用}

核心竞争力是普拉哈拉德和哈默率先提 出的一种管理理论。核心竞争力理论本质上 是一种 “企业素质中心论”。它从企业内在发 展的观点出发分析企业和市场, 揭示出企业 竞争优势的持久源即在于其核心能力。大学 的核心竞争力主要指一个大学在竞争和发展 过程中与其他大学相比较所具有的吸引、争 夺、拥有和控制、转达化资源以及创造社会
价值收益并为其社会提供知识和人才的能 力。大学核心竞争力是一个复杂和多元的由 构成大学竞争力的核心要素整合而成的有机 整体系统。它包含以下几层含义：第一，大 学核心竞争力是一种竞争性的能力, 是一种 相对的竞争强势; 第二, 它是一种处在核心 地位的能力, 是大学其他能力的统领; 第三, 它是长期起作用的能力, 具有随环境的变化 而自我重组、自我适应的特质; 第四, 它是 大学长期孕育、持续积淀而形成的能力, 它 深深地融合在大学的内质之中。可见, 大学 核心竞争力是大学独有的、长期形成并融入 大学内质中支撑大学的竞争优势, 是一个由 其制度体系、学科体系和文化体系有机组合 而成的系统。

中国高等教育发展有一百多年的历史, 大学经历了一个从教学型到研究型、再到现 代大学的多功能型的发展历程。回顾过去, 特别是改革开放以来, 我们会发现, 我国大 学的生存环境发生了巨大变化: 从计划经济 向市场经济的体制转轨; 中国加入 WTO 和高 等教育国际化的趋势; 高等教育管理体制的 不断改革和调整; 高校毕业生就业制度改 革、招生规模扩大、高校合并，等等。这种 全新的环境和以往相比, 最根本的不同, 就 是形成了一种竞争的氛围。伴随新科技革命 的到来, 我国大学的功能和面貌也发生了前 所未有的深刻变化, 高校已成为社会的知识 工厂和思想库, 成为科技进步的 “捊化器” 和社会进步的 “加速器”, 由社会边缘的 “象 牙塔” 变为现代社会的 “轴心机构”。面对大 学之间愈演愈烈的竞争和高校自身担负的越 来越重要的历史使命, 如何培植和提升高校 的核心竞争力, 成为摆在大学管理者面前的 一项不容回避的议题。在新形势下, 大学文 化和大学精神在提高核心竞争力方面愈来愈 发挥重要作用。

首先，大学文化和大学精神可以提高高 校吸引力。大学学术生态环境是大学文化的 一个重要组成部分, 一所大学的学术生态环 境优劣, 直接关系到学校对师资的凝聚力强 弱和吸引力大小。师资“是一个学校的灵魂”, 如果一所大学不能凝聚、吸引一批高水平的 师资, 大学的水平就谈不上, 更不可能超过 其他学校有较大发展。随着人事管理制度的 
改革, 高校教师的自由度和选择余地越来越 大, 哪里能提供更适合发挥才能的学术生态 环境, 就会被哪里所吸引。吸引人才离不开 物质条件, 但关键是学术氛围和文化环境, 对真正的学者来说, 对施展才能舞台的渴求 远远大于对物质利益的追求。许多大学正是 通过优秀的大学文化和大学精神吸引并稳定 了一批高水平师资, 推动了学校的发展。

其次，大学文化和大学精神可以扩大高 校影响力。大学的影响力大小是大学生命力 强弱的标志。一所学校影响力越大, 知名度 越高，其生活空间就越大，辐射面就越广， 生命力也就越强。当前, 很多大学逐渐认识 到这一点, 在对外介绍、宣传自己时, 不再 仅仅做数字上的罗列, 而更多地宣传自己的 特色、理念、精神、价值观和追求目标, 在 宣扬自己成绩和实力的同时, 更加注重自身 文化品位的展示。实践证明, 有特色的大学 文化的确可以提高学校的影响力和美誉度。

再次, 大学文化和大学精神还可以提升 高校自身实力。在计划经济条件下, 大学不 用担心也不存在竞争。随着社会主义市场经 济的逐步确立和高等教育管理体制的改革, 政府在给予大学越来越多自主权的同时也将 竞争机制引入到高等教育的各个领域。大学 文化在激烈的竞争中成为一种强有力的武 器。一所综合实力强大的高校, 必定拥有自 己独特的文化和精神，其大学文化和大学精 神对增强学校竞争力的作用日益凸显, 其竞 争优势也会越来越强。因此, 在新形势下, 引导大学文化的建设和大学精神的培育, 是 完善和建立现代大学制度的重要途径, 是大 学持续、健康、协调发展的重要保证。一所 大学, 必须要倡导和培育先进的大学

文化与大学精神, 建立具有特色的大学 文化战略, 增强大学内部凝聚力, 提高对外 吸引力, 扩大学校影响力, 以大学文化建设 和大学精神的塑造来推进大学核心竞争力的 提高。

\section{4. 培育和提升大学核心竞争力的路径选择}

文化建设是提升大学核心竞争力的源 泉。一所大学的核心竞争力孕育于大学文化 之中, 它可以使大学在竞争中取得源源不断 的可持续生存和发展的能力。笔者认为, 培 育和提升大学核心竞争力, 尤其应当重视以
下几个方面的工作：

一是要把提炼学校的核心价值观和培育 大学精神作为重点。价值观反映了一所大学 的社会追求和远大理想, 大学的核心价值观 是学校一切工作、活动的基础。比如, 很多 高校有自己的校训, 校训其实就是学校价值 观的高度概括和体现。提炼价值观必须从大 学的实际出发, 具有时代特征, 既有很高的 境界, 又符合大学这一组织特性与学校定位, 真正能在学校师生员工中引起共鸣。大学文 化建设的内容十分广泛, 几乎涵盖了大学活 动的一切领域和层面，但其精髓在于培育大 学精神为核心内容的大学意识。大学文化的 核心和灵魂只有一个, 即大学精神。大学文 化建设的关键是从大学的发展历程、优良传 统等方面提炼自己的大学精神, 并且要适应 新形势, 坚持与时俱进, 不断对大学精神进 行丰富和完善, 赋予大学精神新的内涵。在 培育大学精神中要重视共性与个性结合。对 于具体的一所大学来讲, 大学精神具有差异 性, 个性和特色是大学的生命, 因此也是建 设大学精神的关键。大学精神是一所大学的 个性, 并不是每所大学都具有自己独立的大 学精神。大学精神一旦形成, 就将为学校发 展注入坚强的生命底蕴, 并发挥出强有力的 价值导向、群体凝聚和社会辐射等一系列功 能。在中国高等教育一个多世纪的历史中, 不少大学都形成了各具特色的大学精神。例 如, 北京大学以 “提倡新学, 主张思想自由、 兼容并包” 而闻名，清华大学以 “自强不息， 厚德载物” 而传世，北京师范大学以 “学为 人师，行为世范” 而著称。正是既有共性又 极富个性鬼米力的大学精神, 始终坚定不移地 守望着大学精神这块理性王国，才使这些百 年名校经久不衰, 青春常在。

二是要注重提炼学校的办学理念, 注重 发展定位。大学文化具有鲜明的目的性, 紧 紧围绕大学自身为其终极目标服务。大学的 办学理念是大学发展的最终远景与发展方向, 国内外许多一流大学的办学理念都对大学的 发展方向作了明确的勾勒, 办学理念主要阐 明大学的发展规划和使命、大学精神; 科学 定位与发展战略则是大学更为详尽的发展规 划和具体目标。现代社会大学的竞争日趋激 烈，大学只有通过科学的定位，制定合适的 
发展战略, 才能获得更大的发展空间、发展 优势。现在很多学校认识到了这一点, 并认 真研究自己学校的实际情况, 力求对学校的 发展进行正确定位。例如, 清华、北大等学 校将发展目标定位为 “世界一流大学”, 另 有一批实力雄厚的重点大学将发展目标确立 为 “世界知名高水平大学” “国内一流大学” 等, 实力和水平不同, 大学定位也各不相同, 这也是大学文化建设的一个重要方面。

三是要必须不断创新教育理念。作为现 代研究型大学在思考教育理念创新的问题上, 至少应充分考虑到这样几个因素：

一是怎样在观念上真正做到以人为本, 崇尚学术, 追求卓越。对我国大学而言, 必 须坚持学术性价值导向, 建设良好的校园人 文环境, 尊重学术, 尊重人才, 建立良性互 动、和谐共进的人际关系, 为学术发展营造浓 厚的文化氛围。

二是在体制上怎样真正形成以院系为管 理重心、以教师为办学主体、以学生为育人 中心的运行机制。学科是大学的内核, 要提 高大学的核心竞争力, 必须高度重视学科的 内涵的培育, 发展底蕴深厚的学科文化, 着 力营造富有特色的学科文经氛围, 使大学真 正成为学问渊博、学术发达、人才荟萃、潜 力无限的高等学府。

三是怎样与时俱进、抢抓机遇、加快发 展、全面提高学校的办学水平和办学效益。 四是怎样进一步强化科研, 真正把科研与教 学结合起来, 以科研强势带动人才培养, 为 拔尖创新人才的脱颖而出服务, 同时真正把 科研与社会服务结合起来, 为经济发展和民 族振兴做出更大贡献。

\section{5. 是要更加重视大学形象设计, 倡导行为文 化。}

大学形象是公众对某所大学客观现实的 整体印象与评价, 其实质乃是大学客观现实 的外在表现, 是大学办学质量、水平与实力 的中介显示。大学形象是大学的无形名片, 也是一种可贵的文化资源, 是大学在长期的 办学实践中历史性的累积而成的声誉。大学 形象不但影响社会公众对大学的认识, 而且 具有规范大学师生员工的教育行为, 约束大 学的发展方向的作用。大学的办学行为、育 人质量和学术成就等, 并不能自发地转化为
大学形象。它必须经过大学自身的形象设计、 形象宣传和传播媒介的中介造势, 才能广为 人知，深入人心。在市场体制下，面对 WTO 所带来的激烈的高等教育竞争, 大学不能像 以往那样对自身的形象漠然处之, 必须注重 形象设计与建设, 塑造良好的大学形象, 以 增强大学的竞争力。大学形象是大学文化的 外显形态, 有什么样的大学文化, 就有什么 样的大学形象。树立大学形象要从培养优秀 人才入手, 优秀的大学文化最终都会通过自 己的教职员工和毕业生表现出来。行为文化 是在大学的师生、管理服务人员的具体行为 中体现出来的精神品质和气质面貌。在大学 中, 教师刻苦钻研、埋头奋进的身影, 学生 努力拼搏、求实创新的行动, 教学管理人员 勤勤恳恳、热情周到的服务, 都反映出大学 行为文化与众不同的文化魅力。一个良好的 形象是大学的金字招牌, 是大学竞争取胜的 利器。大学形象的塑造不是一朝一夕的事, 涉及大学工作的许多方面, 需要大学内所有 成员齐心协力, 为大学形象的塑造打下一个 好的基础。

\section{6. 结束语}

大学的文化和大学精神是一种博大的精 神财富, 它追求真理、追求自由、倡导民主、 崇尚科学、富于批判。它既是大学发展过程 中的积淀, 也是未来大学的追求; 既在发展 中延伸, 又在延伸中创造。发展是大学永恒 的主题, 高校要想在新时期有所作为、取得 更大的、可持续的发展, 大学核心竞争力是 赢得竞争优势的关键, 大学文化建设和大学 精神的培育就是提升其大学核心竞争力的源 泉。

\section{致谢}

本文为吉林省教育厅 “十二五” 社会科 学研究项目的阶段性成果之一。

\section{References}

[1] University of Yang Dongping Road [M] Shanghai: Wenhui Press, 2003.

[2]University cultural construction of advanced cultural construction [J]China's higher education 2003.1.24.

[3] Theory of university culture and university 
core competitiveness $[\mathrm{J}]$ Beijing education (High version)2003 (12).

[4] University culture and university spirit [A] The university President vision of university education $[\mathrm{C}]$ Beijing:China Renmin University Press.

[5] University culture research review and explore the train of thought [J] China's university teaching,2005 (3). 